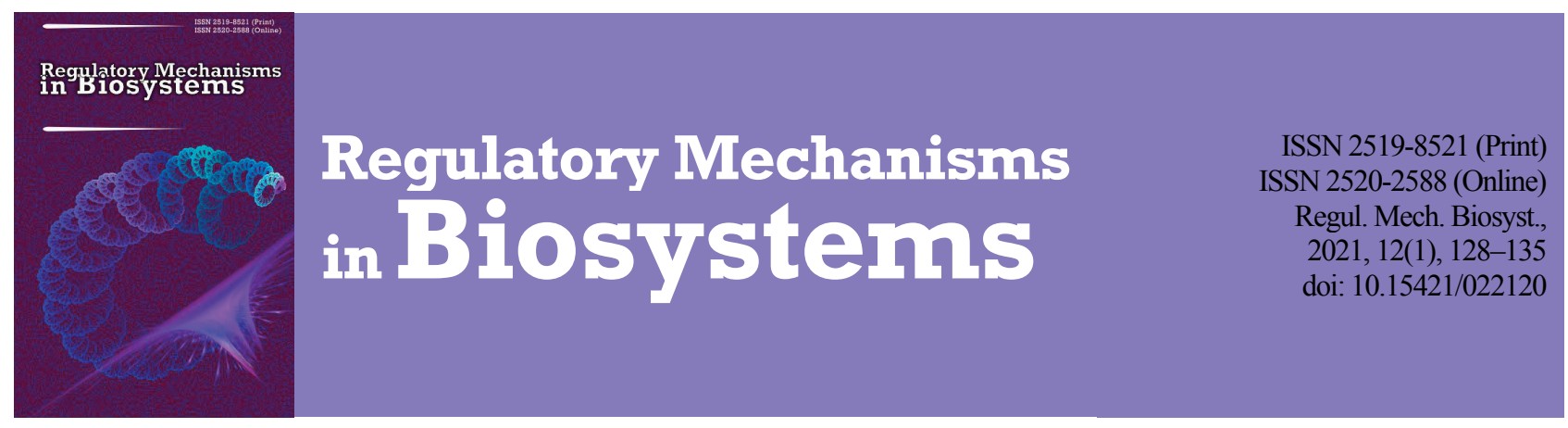

\title{
Intra- and interbreed genetic heterogeneity and divergence in four commercial pig breeds based on microsatellite markers
}

\author{
E. A. Snegin*, A. S. Kramarenko**, O. Y. Artemchuk*, S. S. Kramarenko** \\ *Belgorod National Research University, Belgorod, Russia \\ **Mykolayiv National Agrarian University, Mykolayiv, Ukraine
}

Article info

Received 19.01.2021

Received in revised form 26.02.2021

Accepted 27.02.2021

Belgorod National

Research University

Pobedy st., 85 ,

Belgorod, 308015, Russia.

Tel.: +7-903-642-16-13.

E-mail:snegin@bsu.edu.ru

Mykolayiv National

Agrarian University,

Georgiy Gongadze st., 9,

Mykolayiv, 54020, Ukraine

Tel.: +38-050-991-53-14.

E-mail:

kssnail0108@gmail.com
Snegin, E. A., Kramarenko, A. S., Artemchuk, O. Y., \& Kramarenko, S. S. (2021). Intra- and interbreed genetic heterogeneity and divergence in four commercial pig breeds based on microsatellite markers. Regulatory Mechanisms in Biosystems, 12(1), 128135. doi:10.15421/022120

In recent years, there has been an increasing amount of attention paid to the genetic health of domesticated animals and its relationship with the level of inbreeding and genetic diversity. At the same time, insufficient attention is still paid to the study of intrabreed genetic diversity and intrabreed stratification. The main goal of our work was to analyze the intra- and interbreed genetic diversity of commercial pig breeds on the basis of DNA microsatellite (MS-DNA) polymorphism. In total, the work used data for 3,308 pigs, which represented 11 herds. The animals belonged to four commercial pig breeds - Duroc (DR), Yorkshire (YR), Landrace (LN) and Large White (LW). 12 microsatellite loci recommended by ISAG-FAO and arranged in one multiplex panel (S0101, S0155, S0228, S0355, S0386, SW24, SW240, SW72, SW857, SW911, SW936, SW951) were used as DNA markers. When analyzing the intraand interbreed variability of 11 herds, we found that all studied breeds significantly differed in terms of the proportion of both rare and the most common alleles. At the same time, the noted differences were determined, first of all, by the variability between individual herds within their breed. The location of herd centroids is random and is not consistent with their breed affiliation at all. When individuals belonging to the same breed are combined, the centroids of pig breeds in the space of first two axes from a Principal Coordinate Analysis form two clusters. The first one contains the only red pig breed (DR) used in the analysis, while the second one contains white pig breeds. In six pig herds the Ne estimates were below 50 inds., in two herds they were in the range of 50-100 inds., and finally in three herds the Ne estimates exceeded 100 inds. The analysis of the genetic variability of pigs of four commercial breeds showed that the high level of interbreed differences is caused, first of all, by the high variability among pig herds within each studied breed. Such intrabreed stratification can be formed due to the manifestation of many causes: different genetic basis of the founders of intrabreed genealogical groups, geographical isolation, different directions of selection within individual herds, exchange of animals between separate herds, the use of inbreeding in the practice of selection together with isolation, etc. Important consequences of intrabreed stratification are an increase in the level of interherd diversity (which is not lower than the level of interbreed diversity) against the background of a decrease in variability within individual herds, as well as a significant deficit of heterozygotes and an increase in the role of negative genetic and demographic processes. Thus, the existence of genetic heterogeneity within commercial pig breeds should be considered as an essential element in the history of their formation and breeding.

Keywords: microsatellite DNA loci; intrabreed stratification; commercial pig breeds.

\section{Introduction}

In recent years, an increasing amount of attention has been paid to the genetic health of domesticated animals and its relationship with the level of inbreeding and genetic diversity. This problem is especially manifested in those species of farm animals for which there are negative consequences of the founder effect in the creation of breeds, extensive use of sires and intensive selection, which increase the possibility of genetic abnormalities. An important condition for preventing these negative consequences should be constant genetic monitoring of genetic diversity, intra- and interbreed structure and the degree of inbreeding in the breeds of the main types of farm animals, including pigs (Wiener et al., 2017). In addition, obtaining an adequate evaluation of the genetic structure and diversity of breeds (especially endangered and/or local breeds) is a background for developing a strategy for their conservation (Wilkinson et al., 2011).

Obtaining as complete and reliable information as possible about the level of intrabreed genetic diversity is a key element in the selection of donors when developing a cryopreservation program of germ cells from the most promising sires and dams. However, complete information is not always available to breeders (for example, due to errors in pedigrees), which can lead to inaccurate identification of the intrabreed genetic diversity. Therefore, it is necessary to use other laboratory diagnostic methods, that are more accurate and less dependent on registration errors, for example, the use of highly polymorphic genetic markers - DNA microsatellites (MS-DNA) (Dumasy et al., 2012). Thus, it is necessary to develop optimal management and breeding programs that use genetic data to minimize inbreeding, as programs to maintain overall genetic and allelic diversity and breed identity, and take into account the intrabreed genetic structure (Martínez et al., 2015).

The formation of a complex intrabreed population structure, therefore, cannot be regarded as an exceptional phenomenon for some breeds solely, and such stratification was most often explained by differences in the geographical origin of individual intrabreed groups, different criteria for breeding work, or their joint effect (Chang et al., 2009). To date, there are already many studies devoted to the analysis of intrabreed genetic diversity and the assessment of interbreed differences in the genetic structure of farm animals, incl. pigs (SanCristobal et al., 2006; Sollero et al., 2009). At the same time, insufficient attention is still paid to the study of 
intrabreed genetic diversity and intrabreed stratification. Thus, the main goal of our work was to analyze the intra- and interbreed genetic diversity of commercial pig breeds on the basis of DNA microsatellite polymorphism.

\section{Materials and methods}

In total, the work used data for 3,308 pigs, which represented 11 herds. The animals belonged to the four commercial pig breeds - Duroc (DR), Yorkshire (YR), Landrace (LN) and Large White (LW). Information on the breeds and herds of pigs included in the analysis is presented in Table 1.

Table 1

Information on breeds and herds of pigs included in the analysis

\begin{tabular}{lclc}
\hline \multicolumn{1}{c}{ Breed } & Herd abbreviation & \multicolumn{1}{c}{ Origin of the samples } & Sample size $(n)$ \\
\hline Duroc & DR1 & Russia, Belgorod region & 520 \\
Duroc & DR2 & Russia, Kursk region & 44 \\
Yorkshire & YR1 & Russia, Belgorod region & 420 \\
Yorkshire & YR2 & Russia, Voronezh region & 255 \\
Landrace & LN1 & Russia, Belgorod region & 420 \\
Landrace & LN2 & Russia, Voronezh region & 220 \\
Landrace & LN3 & Russia, Kursk region & 11 \\
Large White & LW1 & Russia, Belgorod region & 420 \\
Large White & LW2 & Russia, Lipetsk region & 192 \\
Large White & LW3 & Russia, Voronezh region & 354 \\
Large White & LW4 & Russia, Kursk region & 452 \\
\hline
\end{tabular}

12 microsatellite loci recommended by ISAG-FAO and arranged in one multiplex panel (S0101, S0155, S0228, S0355, S0386, SW24, SW240, SW72, SW857, SW911, SW936, SW951) were used as DNA markers. Primers for PCR were selected with consideration of the amplification of all 12 loci in one test-tube. The size of all amplified PCR products, taking into consideration all known alleles, was $<300$ base pairs.

The PCR reaction was carried out on a Verity amplifier (Applied Biosystems, USA) in $20 \mu \mathrm{L}$ of a mixture containing $20 \mathrm{ng}$ of genomic DNA, PCR buffer (10 mmol Tris-HCl (pH 8.3), $50 \mathrm{mmol} \mathrm{KCl,} 2 \mathrm{mmol}$ $\left.\mathrm{MgCl}_{2}\right), 0.25 \mathrm{mmol}$ dNTP, $0.5 \mu \mathrm{mol}$ primer, 1 unit. of Taq DNA polymerase (inhibited for hot start). PCR parameters: $94^{\circ} \mathrm{C}-3 \mathrm{~min} ;\left(98^{\circ} \mathrm{C}-30\right.$ s, $\left.59^{\circ} \mathrm{C}-120 \mathrm{~s}, 72{ }^{\circ} \mathrm{C}-90 \mathrm{~s}\right)-4$ cycles; $\left(94^{\circ} \mathrm{C}-30 \mathrm{~s}, 59^{\circ} \mathrm{C}-120 \mathrm{~s}\right.$, $\left.72{ }^{\circ} \mathrm{C}-90 \mathrm{~s}\right)-6$ cycles; $\left(90^{\circ} \mathrm{C}-30 \mathrm{~s}, 59^{\circ} \mathrm{C}-120 \mathrm{~s}, 72{ }^{\circ} \mathrm{C}-75 \mathrm{~s}\right)-$ 20 cycles; $68^{\circ} \mathrm{C}-30 \mathrm{~min}$. In this case, the heating rate from $59^{\circ} \mathrm{C}$ to $72{ }^{\circ} \mathrm{C}$ was no more than $0.3^{\circ} \mathrm{C} / \mathrm{s}$. Fragment analysis of PCR products was performed on an ABI PRISM 3500 automatic capillary DNA sequencer (Applied Biosystems, USA), using $50 \mathrm{~cm}$ capillaries and a POP-7TM polymer matrix. The primers were labeled with four fluorescent dyes detectable in the Blue (FAM), Green (R6G), Yellow (TAMRA), Red (ROX) channels (Table 2).

The length standard SD 450 (Synthol, Russia) was labeled with a fifth, fluorescent dye and was detected in a separate Orange channel simultaneously with PCR products. After amplification, $9 \mu \mathrm{L}$ of Hi-DiTM formamide and $0.5 \mu \mathrm{L}$ of a SD 450 dimensional standard solution were added to $1 \mu \mathrm{L}$ of PCR product. Samples prepared in this way were analyzed on an ABI PRISM 3500 DNA sequencer (Applied Biosystems, USA). Fragment size analysis was performed using GeneMapper $\mathrm{R}$ Software v.4.1 (Applied Biosystems).

Table 2

Characteristics of microsatellite loci recommended by ISAG for determining the reliability of the origin of pigs

\begin{tabular}{lcc}
\hline Locus & Allele length, bp & Dye \\
\hline S0101 & $193-221$ & R6G \\
S0155 & $142-166$ & TAMRA \\
SO228 & $218-270$ & TAMRA \\
S0355 & $223-277$ & FAM \\
SO386 & $164-182$ & FAM \\
SW24 & $93-125$ & ROX \\
SW240 & $93-125$ & R6G \\
SW72 & $97-125$ & TAMRA \\
SW857 & $137-161$ & R6G \\
SW911 & $149-177$ & ROX \\
SW936 & $81-117$ & FAM \\
SW951 & $124-134$ & FAM \\
\hline
\end{tabular}

For each sample of pigs, estimates of the frequencies of genotypes and alleles, the number of alleles $(\mathrm{Na})$, the effective number of alleles (Ae), observed (Ho) and expected (He) heterozygosity, as well as the inbreeding coefficient (Fis) for individual MS-DNA loci were calculated using the GenAIEx v.6.5 program (Peakall \& Smouse, 2012). In addition, the M-ratio (Garza \& Williamson, 2001) estimates were calculated for each herd and MS-DNA locus.

The hypothesis of the absence of significant differences between the studied herds and breeds of pigs in terms of the frequencies of rare and most common alleles was tested using the Pearson Chi-square test in the PAST v. 2.14 software (Hummer et al., 2001). To check the adequacy of genotypes distribution in each MS-DNA locus in each pig herd to the Hardy-Weinberg equilibrium (HWE) based on the likelihood ratio G-test, the PopGen v.1.31 software (Yeh et al., 1999) was used.

To test the hypothesis that there were no significant differences in the indicators of genetic diversity used for individual herds, a non-parametric Friedman two-way ANOVA by ranks using the PAST v. 2.14 software was carried out (Hummer et al., 2001).

Nested two-way ANOVA was used to assess differences within and between individual pig breeds in terms of genetic diversity indicators and M-ratio estimates, considering different MS-DNA loci as independent implementations using the PAST v. 2.14 software (Hummer et al., 2001).

Wright's F-statistic estimates (Fis, Fit and Fst) for each MS-DNA locus and each pig herd were obtained using the GenAIEx v.6.5 program (Peakall \& Smouse, 2012). The significance level of the deviation of the obtained estimates from zero was calculated using the permutation test with 999 permutations. In addition, estimates of the coefficient of genetic differentiation (Fst) were calculated for individual herds within each of the four pig breeds used.

Based on the hierarchical analysis of molecular variance (AMOVA) algorithm for each MS-DNA locus, estimates of $\Phi_{\mathrm{BT}}$ (differentiation between breeds), $\Phi_{\mathrm{PB}}$ (differentiation between herds within their own breed) and $\Phi_{\mathrm{PT}}$ (differentiation between herds) were calculated using the GenAIEx v.6.5 program (Peakall \& Smouse, 2012).

To assess the degree of genetic similarity between herds/breeds of pigs, two approaches were used. First, the Assignment test based on the results of the analysis of microsatellite multilocus genotypes (Paetkau et al., 1995) was carried out both for individual herds of pigs and for individual breeds (all animals of the same breed were combined into one sample) using the GenAIEx v.6.5 program (Peakall \& Smouse, 2012). Secondly, pairwise Nei's genetic distance matrix (Nei, 1972) were calculated for individual herds and breeds, which were used to plot the distribution of centroids of herds/breeds in the space of the first two axes from a Principal Coordinate Analysis (PCoA) using the GenAIEx v.6.5 program (Peakall \& Smouse, 2012).

Estimates of gene flow $(\mathrm{Nm})$ between herds based on the distribution of allele frequencies of 12 MS-DNA loci were obtained using the divMigrate-online program (https://popgen.shinyapps.io/divMigrate-online) (Keenan et al., 2013).

The hypothesis of a bottleneck effect in pig herds in the past with three models (IAM, SMM and TPM) was tested using the BOTTLENECK v.1.2.03 software (Cornuet \& Luikart, 1996). Estimates of the average correlation between alleles ( $r$ ) and the number of cases of linkage disequilibrium (NLD) between individual alleles of 12 MS-DNA loci for pig herds, as well as the results of the Ewens-Watterson test for neutrality were obtained using the PopGen v.1.31 software (Yeh et al., 1999).

Estimates of effective population size in individual pig herds (Ne/Neb) were calculated using the NeEstimator v. 2.0 software (Do et al., 2014). The nonparametric Kruskal-Wallis $\mathrm{H}$ test with the PAST v. 2.14 software (Hummer et al., 2001) was used to test the hypothesis that there were no significant differences in $\mathrm{Ne}$ and Neb estimates between pig breeds.

\section{Results}

In total, when analyzing 12 MS-DNA loci in 11 herds of pigs belonging to four breeds, 188 alleles were noted. The highest allelic diversity was noted among pigs of the LN1, YR1 and LW2 herds (167, 165 and 163 alleles, respectively), and the lowest (63 and 62 alleles) - among pigs 
of the LN3 and DR2 herds, respectively (Table 3). The number of alleles was not associated with the size of sample (Spearman's rank correlation coefficient: $\mathrm{Rs}=0.468 ; \mathrm{n}=11 ; \mathrm{P}=0.147$ ).

More than half of the alleles identified in the studied pig herds (with the exception of LN3 and DR2) were represented by very rare alleles (with a frequency of $\leq 0.050$ ). Wherein estimates of allelic diversity were positively associated with an increased proportion of rare alleles $(\mathrm{Rs}=$ $0.764 ; \mathrm{n}=11 ; \mathrm{P}=0.006$ ) and, on the contrary, negatively associated with an increased proportion of common alleles (i.e., with a frequency of $\geq 0.200$ ) alleles ( $R s=-0.855 ; \mathrm{n}=11 ; \mathrm{P}<0.001)$. Thus, the increasing in the total number of alleles in the studied pig herds occurred due to the increase in the number of rare alleles (Table 3).

All studied pig herds were significantly different from each other in terms of the proportion of both rare and most common alleles (Pearson Chi-square test: in both cases, $\mathrm{P}<0.001)$. However, to a greater extent, these differences were determined by intrabreed variability between individual herds within their breed (in both cases: $\mathrm{P}<0.001$ ) rather than by differences between breeds, which were noted only in relation to the proportion of the most common alleles $\left(\chi^{2}=10.18 ; \mathrm{df}=3 ; \mathrm{P}=0.017\right.$ ) (Table 3 ).

Estimates of indicators of genetic diversity and M-ratio (on average per one locus) in the studied pig herds are given in Table 4. For all these parameters, there are significant associations between the herd and the MS-DNA locus used in the analysis (Friedman two-way ANOVA by ranks: $\mathrm{P}<0.001-0.02)$, i.e., the patterns of variation for individual loci differed significantly in different pig herds.

\section{Table 3}

Total number of alleles (TNA), proportion of rare and common alleles of 12 MS-DNA loci in herds of pigs of different breeds

\begin{tabular}{cccc}
\hline \multirow{2}{*}{ Herd } & \multirow{2}{*}{ TNA } & \multicolumn{2}{c}{ Proportion of alleles with frequency } \\
\cline { 3 - 4 } & & $\leq 0.050$ & $\geq 0.200$ \\
\hline DR1 & 143 & 0.587 & 0.105 \\
DR & 62 & 0.355 & 0.371 \\
YR1 & 165 & 0.539 & 0.085 \\
YR2 & 128 & 0.523 & 0.117 \\
LN1 & 167 & 0.593 & 0.084 \\
LN2 & 137 & 0.584 & 0.131 \\
LN3 & 63 & 0.286 & 0.397 \\
LW1 & 147 & 0.563 & 0.129 \\
LW2 & 163 & 0.650 & 0.135 \\
LW3 & 87 & 0.552 & 0.276 \\
LW4 & 96 & 0.510 & 0.229 \\
\hline & Pearson Chi-square test $\left(\chi^{2} ; P\right)$ & $10.18(0.017)$ \\
\hline Between breeds $(d f=3)$ & - & $3.32(\mathrm{~ns})$ & $72.22(<0.001)$ \\
Between herds within & - & $34.46(<0.001)$ & $82.40(<0.001)$ \\
the breed $(d f=7)$ & - & $37.77(<0.001)$ & \\
Between herds $(d f=10)$ & - & &
\end{tabular}

Note: $\mathrm{ns}-\mathrm{P}>0.05$.

\section{Table 4}

Indicators of genetic diversity and estimates of M-ratio $(\mathrm{x} \pm \mathrm{SE})$ for $12 \mathrm{MS}-\mathrm{DNA}$ loci in herds of pigs of different breeds (on average per one locus)

\begin{tabular}{|c|c|c|c|c|c|c|}
\hline \multirow{2}{*}{ Herd } & \multicolumn{6}{|c|}{ Indicator } \\
\hline & $\mathrm{Na}$ & $\mathrm{Ae}$ & Ho & $\mathrm{He}$ & Fis & M-ratio \\
\hline DR1 & $11.9 \pm 1.0$ & $4.4 \pm 0.6$ & $0.575 \pm 0.073$ & $0.702 \pm 0.052$ & $0.213 \pm 0.070$ & $0.891 \pm 0.042$ \\
\hline DR2 & $5.2 \pm 0.5$ & $2.7 \pm 0.3$ & $0.566 \pm 0.088$ & $0.561 \pm 0.062$ & $-0.011 \pm 0.096$ & $0.679 \pm 0.069$ \\
\hline YR1 & $13.8 \pm 1.1$ & $7.2 \pm 0.8$ & $0.689 \pm 0.052$ & $0.838 \pm 0.021$ & $0.189 \pm 0.050$ & $0.939 \pm 0.040$ \\
\hline YR2 & $10.7 \pm 1.3$ & $4.3 \pm 0.6$ & $0.583 \pm 0.065$ & $0.711 \pm 0.042$ & $0.182 \pm 0.083$ & $0.833 \pm 0.066$ \\
\hline LN1 & $13.9 \pm 1.3$ & $6.7 \pm 0.8$ & $0.675 \pm 0.052$ & $0.824 \pm 0.023$ & $0.193 \pm 0.049$ & $0.944 \pm 0.033$ \\
\hline LN2 & $11.4 \pm 1.6$ & $4.9 \pm 0.9$ & $0.563 \pm 0.065$ & $0.698 \pm 0.059$ & $0.160 \pm 0.094$ & $0.880 \pm 0.051$ \\
\hline LN3 & $5.3 \pm 0.5$ & $3.4 \pm 0.3$ & $0.750 \pm 0.073$ & $0.664 \pm 0.049$ & $-0.118 \pm 0.056$ & $0.702 \pm 0.061$ \\
\hline LW1 & $12.3 \pm 1.0$ & $5.1 \pm 0.4$ & $0.672 \pm 0.049$ & $0.786 \pm 0.022$ & $0.150 \pm 0.051$ & $0.902 \pm 0.034$ \\
\hline LW2 & $13.6 \pm 1.0$ & $4.9 \pm 0.5$ & $0.695 \pm 0.051$ & $0.773 \pm 0.023$ & $0.106 \pm 0.054$ & $0.939 \pm 0.025$ \\
\hline LW3 & $7.3 \pm 0.8$ & $2.8 \pm 0.2$ & $0.604 \pm 0.094$ & $0.608 \pm 0.040$ & $0.034 \pm 0.138$ & $0.716 \pm 0.055$ \\
\hline LW4 & $8.0 \pm 0.9$ & $3.4 \pm 0.4$ & $0.617 \pm 0.076$ & $0.664 \pm 0.035$ & $0.103 \pm 0.095$ & $0.789 \pm 0.064$ \\
\hline $\begin{array}{l}\text { Friedman two-way ANOVA } \\
\text { by ranks }\left(\chi^{2} ; P ; d f=10\right)\end{array}$ & $\begin{array}{c}76.05 \\
(<0.001)\end{array}$ & $\begin{array}{c}58.00 \\
(<0.001)\end{array}$ & $\begin{array}{c}21.23 \\
(0.020)\end{array}$ & $\begin{array}{c}57.77 \\
(<0.001)\end{array}$ & $\begin{array}{c}31.49 \\
(<0.001)\end{array}$ & $\begin{array}{c}36.21 \\
(<0.001)\end{array}$ \\
\hline
\end{tabular}

Table 5

Results of nested two-way ANOVA of genetic diversity indicators and M-ratio (F; P) estimates of 12 MS-DNA loci in herds of pigs of different breeds

\begin{tabular}{|c|c|c|c|c|c|c|}
\hline \multirow{2}{*}{ Source } & \multicolumn{6}{|c|}{ Indicator } \\
\hline & $\mathrm{Na}$ & $\mathrm{A}$ & Ho & $\mathrm{He}$ & Fis & M-ratio \\
\hline Between breeds $\left(d f_{1}=3 ; d f_{2}=121\right)$ & $3.64(0.015)$ & $6.44(<0.001)$ & 0.79 (ns) & $4.17(0.008)$ & 0.78 (ns) & 1.35 (ns) \\
\hline Between herds within the breed $\left(d f_{1}=7 ; d f_{2}=121\right)$ & $11.15(<0.001)$ & $6.39(<0.001)$ & 0.88 (ns) & $4.51(<0.001)$ & 1.99 (ns) & $5.12(<0.001)$ \\
\hline Between herds $\left(d f_{1}=10 ; d f_{2}=121\right)$ & $8.90(<0.001)$ & $6.40(<0.001)$ & 0.86 (ns) & $4.41(<0.001)$ & 1.63 (ns) & $3.99(<0.001)$ \\
\hline
\end{tabular}

The average number of alleles (Na) per locus, as expected, was the highest in LN1, YR1, and LW2 herds (13.9, 13.8 and 13.2 alleles per locus, respectively), and the lowest in LN3 and DR2 herds (5.3 and 5.2 alleles per locus, respectively). The average number of effective alleles (Ae) per locus did not completely repeat the results obtained above - the maximum value was noted in LN1 and YR1 herds (7.2 and 6.7 alleles per locus, respectively), and the lowest - in LW3 and DR2 herds (2.8 and 2.7 alleles per locus, respectively, Table 4 ).

Average estimates of observed heterozygosity ( $\mathrm{Ho}$ ) varied from 0.563 (LN2 herd) to 0.750 (LN3 herd), while estimates of expected heterozygosity $(\mathrm{He})$ varied over a wider range, from 0.561 (DR2 herd) to 0.838 (YR1 herd). In two cases (for DR2 and LN3 herds) we noted an excess of observed heterozygosity over expected, which led to negative estimates of the inbreeding coefficient (Fis $=-0.011$ and Fis $=-0.118$, respectively), while in most cases the deficit of heterozygosity was accompanied by positive estimates of the inbreeding coefficient on average per locus, which varied from 0.034 (LW3 herd) to 0.213 (DR1 herd) (Table 4).

The decrease in allelic diversity, which was most noted for pigs of LN3 and DR2 herds, manifests itself against the background of maintai- ning the same wide interval of alleles as for groups of animals with the maximum number of identified alleles, which leads to a sharp decrease in M-ratio estimates. Thus, only for LN3 and DR2 herds, the obtained estimates of the M-ratio (on average per locus) did not significantly deviate from the critical value of 0.600 (Garza \& Williamson, 2001), while in the other studied groups these estimates reliably exceeded it (Table 4).

The results of the nested two-way ANOVA of genetic diversity indicators and M-ratio estimates, taking into account different loci of MSDNA, as independent realizations, show high homogeneity for different breeds/herds of pigs with respect to observed heterozygosity (Ho) and inbreeding coefficient (Fis) (Table 5). Whereas, for the rest of the indicators used, a high level of interherd diversity was noted, which was determined, to a greater extent, by intrabreed differences between individual herds within their breed (in all cases: $\mathrm{P}<0.001$ ), and not by differences between breeds $(\mathrm{P}<0.001-0.015)$. In relation to the M-ratio estimates, there was no reliable difference between the breeds (Table 5).

Significant differences were noted with respect to the distribution of allele frequencies of MS-DNA loci among individual herds for all four studied pig breeds. The Fst estimates varied from 0.067 (for two herds of the YR breed) to 0.168 (for two herds of the DR breed), but in all cases Fst 
estimates significantly differed from zero $(\mathrm{P}<0.001$, Table 6 ). When uniting individuals belonging to the same breed, the estimate of interbreed genetic differentiation was even lower than when comparing herds for individual breeds $(\mathrm{Fst}=0.065)$, although it also significantly differed from zero $(\mathrm{P}<0.001)$.

The results of testing of Hardy-Weinberg equilibrium demonstrate significant interherd differences (Table 7). For DR1, YR1, YR2, LN1, LW1, LW4 herds, all MS-DNA loci used in the analysis demonstrated a significant deviation from the HWE, while for DR2 and LN3 herds, on the contrary, the overwhelming majority of loci were in the HWE. If analyzed in relation to individual MS-DNA loci, then for loci SW936 and SW951, for 10 out of 11 studied pig herds, a significant deviation from the HWE was noted, while for other herds the number of such loci was 7-9 (Table 7).

\section{Table 6}

Fst estimates for 12 MS-DNA loci among individual herds for the four pig breeds studied

\begin{tabular}{cccc}
\hline Breed & Number of herds & Fst & P \\
\hline DR & 2 & 0.168 & $<0.001$ \\
YR & 2 & 0.067 & $<0.001$ \\
LN & 3 & 0.108 & $<0.001$ \\
LW & 4 & 0.121 & $<0.001$ \\
\hline
\end{tabular}

Table 7

Results of testing of Hardy-Weinberg equilibrium (HWE) for 12 loci of MS-DNA in herds of pigs of different breeds based on the likelihood ratio G-test

\begin{tabular}{|c|c|c|c|c|c|c|c|c|c|c|c|}
\hline \multirow{2}{*}{ Locus } & \multicolumn{11}{|c|}{ Herd } \\
\hline & DR1 & DR2 & YR1 & YR2 & LN1 & LN2 & LN3 & LW1 & LW2 & LW3 & LW4 \\
\hline$S 0101$ & $<0.001$ & $\mathrm{~ns}$ & $<0.001$ & $<0.001$ & $<0.001$ & $<0.001$ & ns & $<0.001$ & ns & 0.009 & $<0.001$ \\
\hline SO155 & $<0.001$ & $\mathrm{~ns}$ & $<0.001$ & $<0.001$ & $<0.001$ & ns & ns & $<0.001$ & $<0.001$ & ns & $<0.001$ \\
\hline SO228 & $<0.001$ & 0.041 & $<0.001$ & 0.018 & 0.001 & ns & ns & $<0.001$ & ns & 0.008 & $<0.001$ \\
\hline SO355 & $<0.001$ & $\mathrm{~ns}$ & $<0.001$ & $<0.001$ & $<0.001$ & $<0.001$ & ns & $<0.001$ & $<0.001$ & ns & $<0.001$ \\
\hline S0386 & $<0.001$ & 0.003 & $<0.001$ & $<0.001$ & $<0.001$ & $<0.001$ & ns & $<0.001$ & $<0.001$ & $<0.001$ & $<0.001$ \\
\hline$S W 24$ & $<0.001$ & ns & $<0.001$ & $<0.001$ & $<0.001$ & $<0.001$ & ns & $<0.001$ & $<0.001$ & $<0.001$ & $<0.001$ \\
\hline$S W 240$ & $<0.001$ & ns & $<0.001$ & $<0.001$ & $<0.001$ & $<0.001$ & ns & $<0.001$ & $<0.001$ & $<0.001$ & $<0.001$ \\
\hline$S W 72$ & $<0.001$ & ns & $<0.001$ & 0.017 & $<0.001$ & ns & ns & $<0.001$ & $<0.001$ & ns & 0.007 \\
\hline SW857 & $<0.001$ & $\mathrm{~ns}$ & $<0.001$ & $<0.001$ & $<0.001$ & $<0.001$ & ns & $<0.001$ & ns & 0.024 & $<0.001$ \\
\hline SW911 & $<0.001$ & ns & $<0.001$ & $<0.001$ & $<0.001$ & $<0.001$ & ns & $<0.001$ & $<0.001$ & $<0.001$ & 0.002 \\
\hline SW936 & $<0.001$ & $<0.001$ & $<0.001$ & $<0.001$ & $<0.001$ & $<0.001$ & 0.027 & $<0.001$ & ns & $<0.001$ & $<0.001$ \\
\hline SW951 & $<0.001$ & $<0.001$ & $<0.001$ & $<0.001$ & $<0.001$ & $<0.001$ & ns & $<0.001$ & $<0.001$ & $<0.001$ & $<0.001$ \\
\hline
\end{tabular}

The results of hierarchical analysis of molecular variance (AMOVA) showed that there are significant differences in the distribution of allele frequencies of 12 MS-DNA loci between the studied pig herds (Table 8). The average estimate of interherd genetic differentiation (ФPT) is $0.237 \pm$ $0.018(\mathrm{P}<0.001)$, with a range for the different loci of MS-DNA used from 0.140 (locus SW240) to 0.323 (locus SW72). We did not identify significant differences between the pig breeds included in the analysis $(\Phi B T=0.005 \pm 0.014 ; \mathrm{P}>0.05)$ and most of the interherd variability is due to intrabreed differences between pig herds within their breed $(\Phi \mathrm{PB}=$ $0.233 \pm 0.019 ; \mathrm{P}<0.001)$ (Table 8).

\section{Table 8}

Results the hierarchical analysis of molecular variance (AMOVA) of 12 MS-DNA loci in herds of pigs of different breeds

\begin{tabular}{lccc}
\hline \multirow{2}{*}{ Locus } & \multicolumn{3}{c}{ Indicator } \\
\cline { 2 - 4 } & $\Phi_{\mathrm{BT}}$ & $\Phi_{\mathrm{PB}}$ & $\Phi_{\mathrm{PT}}$ \\
\hline S0101 & 0.027 & 0.190 & 0.212 \\
S0155 & 0.028 & 0.235 & 0.257 \\
S0228 & -0.086 & 0.283 & 0.221 \\
S0355 & 0.041 & 0.313 & 0.341 \\
S0386 & 0.002 & 0.147 & 0.149 \\
SW24 & 0.003 & 0.234 & 0.236 \\
SW240 & 0.001 & 0.152 & 0.140 \\
SW72 & 0.001 & 0.323 & 0.323 \\
SW857 & 0.109 & 0.138 & 0.232 \\
SW911 & -0.005 & 0.199 & 0.195 \\
SW936 & -0.058 & 0.305 & 0.264 \\
SW951 & -0.001 & 0.275 & 0.274 \\
\hline \multicolumn{1}{c}{$\mathrm{x} \pm$ SE } & $0.005 \pm 0.014$ & $0.233 \pm 0.019$ & $0.237 \pm 0.018$ \\
\multicolumn{1}{c}{$\mathrm{P}$} & $\mathrm{ns}$ & $<0.001$ & $<0.001$ \\
\hline
\end{tabular}

The high originality of the genetic structure in individual pig herds was also confirmed by the results of the Assignment test based on the distribution of MS-DNA multilocus genotypes (Table 9). The genetic uniqueness of pig herds varied from $72.4 \%$ (LN1 herd) to $100 \%$ (DR2 herd) and on average was $86.2 \%$. For pigs of the DR and LW breeds, among all the wrongly assigned individuals, almost a third $(29.1 \%$ and $27.4 \%$, respectively) were wrongly assigned to another herd, but of their own breed. For YR and LN pigs, only $6.5 \%$ and $14.5 \%$ were wrongly assigned to another herd of their breed, respectively, while the rest were wrongly assigned to other breeds.

When individuals belonging to the same breed were combined, the average genetic uniqueness of pig breeds included in the analysis was
$82.0 \%$, i.e., it was slightly lower than one for pig herds (Table 10 ). The assignment accuracy varied from $66.5 \%$ (breed YR) to $89.4 \%$ (breed LW). For none of the investigated breeds, did the assignment accuracy of individuals exceed $90 \%$, whereas for pig herds, in seven of 11 cases the level of genetic originality of the group exceeded $90 \%$ (Tables 9 and 10 ).

The degree of similarity of the genetic structure of pigs was assessed using the distribution of centroids of herds/breeds in the space of first two axes from a Principal Coordinate Analysis ( $\mathrm{PCoA}$ ) based on the pairwise Nei's genetic distance matrix (Fig. 1). The location of herd centroids is random and is not consistent with their breed affiliation at all. The two herds of Duroc (DR1 and DR2) were the most distant from each other, and the smallest genetic distance was noted for herds representing Duroc (DR2) and Landrace (LN3) breeds (Fig. 1a).

\section{Table 9}

Results of the Assignment test between herds of pigs of different breeds based on the distribution of MS-DNA multilocus genotypes

\begin{tabular}{lcccccccccccc}
\hline $\begin{array}{l}\text { Herd } \\
\text { (fact) }\end{array}$ & DR1 & DR2 & YR1 & YR2 & LN1 & LN2 & LN3 & LW1 & LW2 & LW3 & LW4 & Assignment \\
accuracy,\%
\end{tabular}

\section{Table 10}

Results of the Assignment test between pooled samples of different breeds of pigs based on the frequency distribution of MS-DNA multilocus genotypes

\begin{tabular}{|c|c|c|c|c|c|}
\hline \multirow{2}{*}{$\begin{array}{c}\text { Breed } \\
\text { (fact) }\end{array}$} & \multicolumn{4}{|c|}{ Breed (predicted) } & \multirow{2}{*}{$\begin{array}{l}\text { Assignment } \\
\text { accuracy, } \%\end{array}$} \\
\hline & DR & YR & LN & LW & \\
\hline DR & 444 & 52 & 50 & 18 & 78.7 \\
\hline YR & 94 & 449 & 105 & 27 & 66.5 \\
\hline $\mathrm{LN}$ & 19 & 51 & 552 & 29 & 84.8 \\
\hline LW & 18 & 90 & 42 & 1268 & 89.4 \\
\hline
\end{tabular}


When individuals belonging to the same breed are combined, the centroids of pig breeds in the space of first two axes from a Principal Coordinate Analysis form two clusters (Fig. 1b). The first one contains the only red pig breed (DR) used in the analysis, while the second one contains white pig breeds (YR, LN and LW). Although along the second Principal Coordinate (axis) there is a significant differentiation between the YR and LN breeds, on the one hand, and the LW breeds, on the other (Fig. 1b).

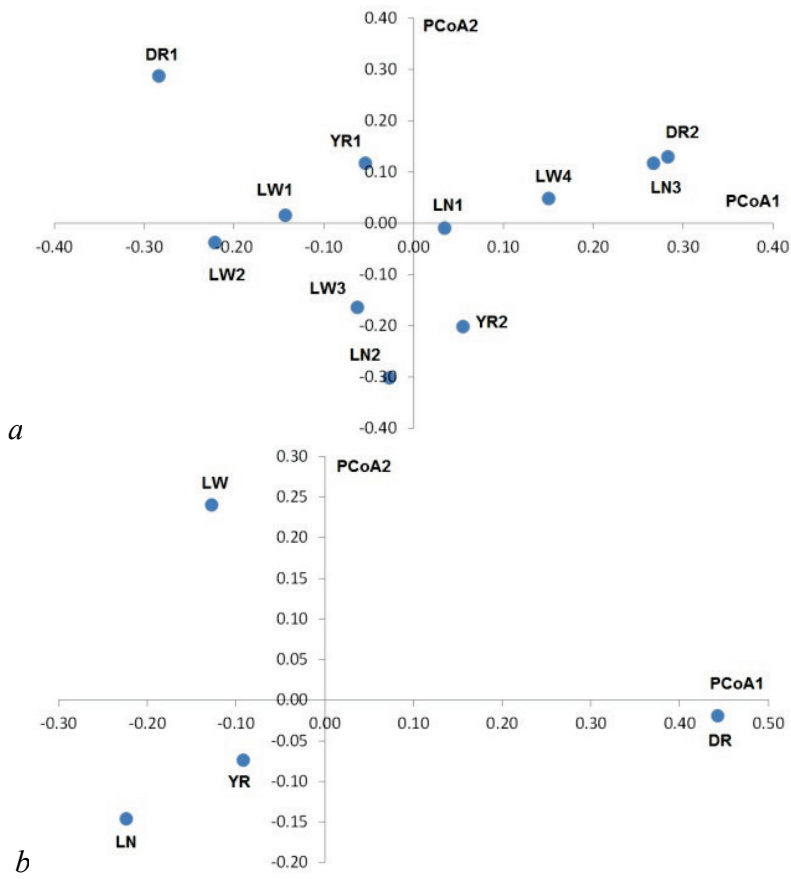

Fig. 1. Distribution of centroids of herds/breeds in the space of first two axes from a Principal Coordinate Analysis (PCoA) based on the pairwise Nei's genetic distance matrix: $a$ - for 11 pig herds of different breeds; $b$ - for four pig breeds (based on combined samples)

Gene flow estimates $(\mathrm{Nm})$ showed the presence of an intensive exchange of genetic information between LW herds from different regions of the Russian Federation, as well as between animals kept in different herds, but within the same farm, for example, from the Belgorod region (Fig. 2).

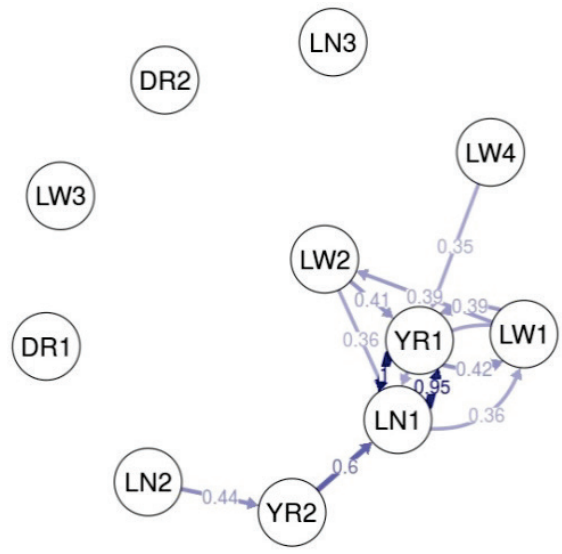

Fig. 2. Estimates of the gene flow $(\mathrm{Nm})$ between herds of pigs of different breeds based on the distribution of allele frequencies of 12 MS-DNA loci (threshold value $\mathrm{Nm} \geq 0.35$ ind./year)

An extensive gene flow was noted primarily among white pig breeds (YR, LN and LW). Apparently, this fact can partially explain the genetic similarity at the breed level (Fig. 1b), as well as the presence of a large number of wrong assignments of individuals to their herd or their breed (Tables 9 and 10).

The testing results of the hypothesis about the presence of the bottleneck effect for pig herds of different breeds in the past are shown in Table 11.
The use of the IAM model allows us to reject the hypothesis about the possible impact of the bottleneck effect for all pig herds included in the analysis. The use of the SMM model, on the contrary, in seven of 11 cases allows us to accept this hypothesis. This model provides a basis for accepting the hypothesis about the consequences of the bottleneck effect in five herds, represented by pigs of all breeds included in the analysis (DR1, YR1, LN1, LN2 and LW1) (Table 11).

Table 11

Testing results of the hypothesis about the presence of bottleneck effect for pig herds of different breeds in the past, based on estimates of heterozygosity of 12 MS-DNA loci (the theoretically expected/observed number of loci that exhibit excess of heterozygosity are shown)

\begin{tabular}{cccc}
\hline \multirow{2}{*}{ Herd } & \multicolumn{3}{c}{ Model } \\
\cline { 2 - 4 } & IAM & TPM & SMM \\
\hline DR1 & $7.10 / 6(\mathrm{~ns})$ & $7.07 / 3(P=0.018)$ & $6.99 / 1(P<0.001)$ \\
DR2 & $6.72 / 8(\mathrm{~ns})$ & $6.90 / 6(\mathrm{~ns})$ & $6.94 / 5(\mathrm{~ns})$ \\
YR1 & $7.24 / 7(\mathrm{~ns})$ & $7.09 / 3(P=0.018)$ & $7.06 / 1(P<0.001)$ \\
YR2 & $7.06 / 6(\mathrm{~ns})$ & $7.10 / 6(\mathrm{~ns})$ & $7.02 / 1(P<0.001)$ \\
LN1 & $7.27 / 6(\mathrm{~ns})$ & $7.12 / 2(P=0.003)$ & $7.05 / 0(P<0.001)$ \\
LN2 & $7.00 / 4(\mathrm{~ns})$ & $7.06 / 3(P=0.019)$ & $7.06 / 1(P<0.001)$ \\
LN3 & $6.89 / 8(\mathrm{~ns})$ & $7.05 / 8(\mathrm{~ns})$ & $7.14 / 8(\mathrm{~ns})$ \\
LW1 & $7.16 / 8(\mathrm{~ns})$ & $7.06 / 3(P=0.019)$ & $7.01 / 1(P<0.001)$ \\
LW2 & $7.25 / 6(\mathrm{~ns})$ & $7.09 / 4(\mathrm{~ns})$ & $7.04 / 3(P=0.019)$ \\
LW3 & $6.86 / 9(\mathrm{~ns})$ & $6.95 / 6(\mathrm{~ns})$ & $7.09 / 4(\mathrm{~ns})$ \\
LW4 & $6.94 / 8(\mathrm{~ns})$ & $7.04 / 7(\mathrm{~ns})$ & $7.11 / 4(\mathrm{~ns})$ \\
\hline
\end{tabular}

Despite the fact that a-priori MS-DNA are neutral genetic markers, we found that nine of 11 studied pig herds had loci for which the null hypothesis of neutrality was rejected based on the results of the EwensWatterson test (Table 12). Most of these loci were found in herds YR1 (seven loci) and LN1 (four loci). Only for locus S0155, did we never observe a significant deviation from neutrality, while such a deviation was noted for loci SW24, SW240, SW936 (in three pig herds) and SW857 (in five pig herds, Table 12). Most often, MS-DNA loci that significantly deviated from neutrality were found among pigs of YR ( 9 out of 24 loci, i.e., $37.5 \%$ ) and LN breeds (7 out of 36 loci, i.e., 19.4\%, Table 12).

Table 12

Results of the Ewens-Watterson test for 12 MS-DNA loci for different herds of pigs of different breeds (only loci for which the hypothesis of neutrality is reliably rejected are shown)

\begin{tabular}{cccc}
\hline Herd & Locus & Obs. F & L95-U95 \\
\hline DR1 & SW240 & 0.131 & $0.160-0.651$ \\
DR2 & SW936 & 0.254 & $0.306-0.891$ \\
& S0228 & 0.081 & $0.105-0.399$ \\
& S0355 & 0.149 & $0.152-0.620$ \\
YR1 & SW24 & 0.108 & $0.143-0.587$ \\
& SW240 & 0.111 & $0.145-0.575$ \\
& SW72 & 0.158 & $0.160-0.591$ \\
& SW857 & 0.140 & $0.158-0.661$ \\
YR2 & SW936 & 0.097 & $0.140-0.574$ \\
& SW857 & 0.132 & $0.158-0.645$ \\
& SW911 & 0.180 & $0.185-0.698$ \\
LN1 & S0228 & 0.081 & $0.100-0.350$ \\
& SW24 & 0.117 & $0.148-0.605$ \\
& SW240 & 0.089 & $0.137-0.517$ \\
& SW72 & 0.155 & $0.156-0.649$ \\
LN2 & S0101 & 0.123 & $0.130-0.509$ \\
& S0386 & 0.147 & $0.173-0.715$ \\
LW1 & SW857 & 0.091 & $0.150-0.548$ \\
LW2 & SW24 & 0.139 & $0.173-0.665$ \\
& SW857 & 0.116 & $0.144-0.519$ \\
LW4 & SW951 & 0.284 & $0.347-0.954$ \\
& SW857 & 0.240 & $0.252-0.890$ \\
& SW936 & 0.169 & $0.258-0.882$ \\
\hline
\end{tabular}

Note: Obs. F is the actual sum of the squares of the allele frequencies; L95, U95 lower and upper values of the $95 \%$ confidence interval of the Obs. F estimate calculated based on 1000 simulations.

Estimates of the effective population size (Ne) obtained for the studied pig herds indicate an unfavourable state of the level of their genetic variability, which is apparently caused by a high level of inbreeding. Six 
herds had Ne values below 50 inds. (assuming a 95\% confidence interval), two herds had Ne values in the 50-100 inds., and finally, three herds had Ne values greater than 100 inds. (Table 13).

Table 13

Estimates of the effective population size for pig herds of different breeds, calculated on the basis of the LD- and MC-method using 12 MS-DNA loci (the boundaries of the $95 \%$ confidence interval are shown)

\begin{tabular}{ccc}
\hline \multirow{2}{*}{ Herd } & \multicolumn{2}{c}{ Method } \\
\cline { 2 - 3 } & LD $(\mathrm{Ne})$ & Molecular Coancestry $(\mathrm{Neb})$ \\
\hline DR1 & $18.1(16.4-19.8)$ & $2.3(1.4-3.4)$ \\
DR2 & $22.6(15.0-36.1)$ & $2.3(0.8-4.7)$ \\
YR1 & $29.4(27.1-31.9)$ & $10.7(7.3-14.8)$ \\
YR2 & $48.6(40.3-58.5)$ & $3.5(2.3-4.8)$ \\
LN1 & $40.5(35.7-45.7)$ & $11.4(8.3-15.0)$ \\
LN2 & $110.2(76.4-168.8)$ & $6.4(3.6-9.8)$ \\
LN3 & $37.4(16.3-\infty)$ & $13.7(3.3-31.2)$ \\
LW1 & $20.4(18.6-22.4)$ & $3.8(3.1-4.5)$ \\
LW2 & $35.6(29.6-42.9)$ & $6.7(4.0-10.2)$ \\
LW3 & $83.8(50.5-142.9)$ & $172.5(0.2-865.7)$ \\
LW4 & $38.2(25.3-55.7)$ & $3.6(2.6-4.9)$ \\
\hline
\end{tabular}

Estimates of the effective number of sires (Neb) obtained using the Molecular Coancestry method (MC) were almost an order of magnitude lower. In five herds, the Neb values did not exceed 5 inds., in another five, the Neb values were in the range of 5-20 inds., and only in one herd (LW3) did the estimate of the effective number of sires exceed one hundred inds. (Table 13).

In general, no significant differences in the $\mathrm{Ne}$ and $\mathrm{Neb}$ estimates between the pig breeds included in the analysis were identified (KruskalWallis $\mathrm{H}$ test: in both cases $\mathrm{P}>0.05$ ). Whereas significant intrabreed differences were noted between individual herds of YR, LN and LW breeds, but only in relation to Ne estimates (Table 13).

A high level of inbreeding is also confirmed by a significant number of linkage disequilibrium (NLD) between alleles of 12 MS-DNA loci recorded in most of the studied pig herds, especially in LW1, DR1, YR1 and LN1 (1299, 1247, 1164 and 800 cases, respectively, Table 14). There was no significant difference between the studied breeds in terms of NLD estimates for individual herds of pigs (Kruskal-Wallis $\mathrm{H}$ test: $\mathrm{H}=1.26$; $\mathrm{P}>0.05$ ).

The estimates of the average correlation between alleles ( $\mathrm{r}$ ) of the MS-DNA loci varied from 0.082 (LW3 herd) to 0.345 (DR1 herd) and in all cases (except for LN3 herd) significant exceeded zero (Table 14). There was no significant difference between the studied breeds in terms of $r$ estimates for individual herds of pigs (Kruskal-Wallis $\mathrm{H}$ test: $\mathrm{H}=3.89$; $\mathrm{P}>0.05)$. As expected, an inverse dependence of the estimates of the average correlation between alleles (r) in different pig herds on the effective population size $(\mathrm{Ne})$ for these herds was noted (Spearman's rank correlation coefficient: $\mathrm{Rs}=-0.609 ; \mathrm{n}=11 ; \mathrm{P}=0.047$, Fig. 3).

\section{Discussion}

When analyzing the intra- and interbreed variability of 11 herds, which belonged to four commercial pig breeds, in relation to $12 \mathrm{Ms}-\mathrm{DNA}$ loci, we found that all studied breeds significantly differed in terms of the proportion of both rare and the most common alleles. At the same time, the noted differences were determined, first of all, by the variability between individual herds within their breed (Table 3). In addition, for all indicators of genetic diversity used (with the exception of Ho and Fis), a high level of interherd heterogeneity was noted, which was also more determined by intrabreed differences between individual herds within their breed than by differences between breeds (Table 5). Although some authors consider the manifestation of intrabreed stratification to be relatively rare for farm animals (Wilkinson et al., 2012), it was previously noted for horses (Glowatzki-Mullis et al., 2006), cows (Lazebnaya et al., 2020), pigs (Wilkinson et al., 2011), goats (Martínez et al., 2015), chickens (Wilkinson et al., 2012), dogs (Chang et al., 2009; Wiener et al., 2017) and rabbits (Jochová et al., 2017). At the same time, the existence of intrabreed genetic heterogeneity should not be viewed exclusively as a negative phenomenon, but as an essential element in the history of their creation (European ..., 2006).
Table 14

Estimates of the mean correlation between alleles $(r)$ and the number of linkage disequilibrium (NLD) between alleles of 12 MS-DNA loci for herds of pigs of different breeds

\begin{tabular}{lccrrr}
\hline \multicolumn{1}{c}{ Herd } & $\mathrm{r}$ & $\mathrm{df}$ & \multicolumn{1}{c}{$\chi^{2}$} & $\mathrm{P}$ & $\mathrm{N}_{\mathrm{LD}}$ \\
\hline DR1 & 0.345 & 66 & 1727.46 & $<0.001$ & 1247 \\
DR2 & 0.339 & 66 & 138.37 & $<0.001$ & 20 \\
YR1 & 0.291 & 66 & 991.82 & $<0.001$ & 1164 \\
YR2 & 0.327 & 66 & 747.57 & $<0.001$ & 264 \\
LN1 & 0.175 & 66 & 440.49 & $<0.001$ & 800 \\
LN2 & 0.198 & 66 & 282.39 & $<0.001$ & 140 \\
LN3 & 0.533 & 45 & 57.44 & $\mathrm{~ns}$ & 0 \\
LW1 & 0.318 & 66 & 1161.62 & $<0.001$ & 1299 \\
LW2 & 0.263 & 66 & 414.10 & $<0.001$ & 448 \\
LW3 & 0.082 & 66 & 106.66 & 0.002 & 56 \\
LW4 & 0.179 & 66 & 488.97 & $<0.001$ & 179 \\
\hline
\end{tabular}

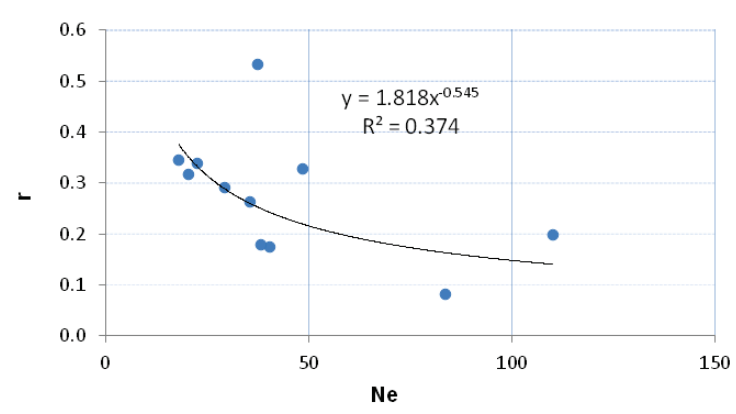

Fig. 3. Dependence of the estimates of the average correlation (r) between alleles of 12 MS-DNA loci on the effective population size $(\mathrm{Ne})$ of herds of pigs of different breeds

The observed level of intrabreed diversity can be explained by the different genetic basis of the founders of intrabreed genealogical groups (sire/dam lines), geographical isolation, natural selection, as well as the breeding methods used, including the exchange of animals between individual herds (Dumasy et al., 2012). In Martínez et al. (2015), geographic isolation was also indicated as the main factor that determined the formation of genetic intrabreed stratification of local goat breeds in Spain and Portugal. The genetic divergence of the Lithuanian White-Backed cattle was the result of the combined influence of artificial selection, geographic origin, and the presence of admixtures of other breeds during the formation of this breed (Šveistienė \& Jatkauskienè, 2008). We also noted a significant number of admixtures for the analyzed groups of pigs: at the level of individual herds $-0-31.0 \%$ (Table 9), and at the level of individual breeds $-10.6-33.5 \%$ (Table 10 ).

A high level of intrabreed stratification can also be associated with the farm animal productivity; in the dual-purpose breeds the level of intrabreed differentiation was higher (Lazebnaya er al., 2020). Wiener et al. (2017) noted a high withinbreed genetic differentiation in the Labrador Retriever dog breed, which was a consequence of the different direction of breeding (working, pet, show), and with respect to different coat colours (black, yellow, brown). Björnerfeldt et al. (2008) found significant genetic differentiation in the Poodle breed associated with both size and coat colour. A different direction of selection within individual breeds (and herds) can also be observed for the pigs we analyzed, which was reflected in a significant deviation of the studied MS-DNA loci from the neutrality (Table 12). Thus, almost all studied pig herds demonstrate the results of the action of multidirectional selection vectors. It has already been noted that there is a correlation between the presence/absence of some alleles of MS-DNA loci and the productivity of pigs (Chmurzynska et al., 2004; Korwin-Kossakowska et al., 2004; Li et al., 2008; Lugovoy et al., 2018).

For the Leghorn and Sussex chicken breeds, the manifestation of intrabreed stratification was associated with morphological differences within the breed groups, while for other poultry breeds it was primarily associated with management, with different suppliers of breeding material, as a result of which all individuals in a certain herd were genetically separated from the rest of the chickens of the same breed (Wilkinson et al., 2012). The presence of intrabreed stratification, noted in a number of studies, is also formed due to the use of inbreeding in the practice of bree- 
ding together with isolation, which manifests itself for populations of different origins and can prevent gene flow and provide genetic differentiation even among individuals of the same breed (Alves et al., 2015). Previously, similar observations were described for dogs (Chang et al., 2009) and sheep (Kijas et al., 2009). In addition, using the example of rabbit breeds, it has been shown (Alves et al., 2015) that continuous and differentiated artificial selection, together with modern breeding that maintains breeds as closed genetic pools, can transform genetic uniformity into a set of highly differentiated genetic interbreed groups.

For most of the studied herds and breeds of pigs, a significant deficit of heterozygotes was noted (Table 4). It has already been noted that, along with inbreeding and genetic drift, the manifestation of which is primarily associated with the small size of populations, the deficit of heterozygotes may also be associated with intrabreed stratification (Martínez et al., 2015). In addition, for rabbit breeds, the revealed intrabreed stratification was accompanied by a significant deviation of the distribution of genotype frequencies from the HWE, as well as high positive Fis estimates (Jochová et al., 2017). In our study, for DR1, YR1, YR2, LN1, LW1, LW4 herds, all the MS-DNA loci used demonstrated a significant deviation from the HWE (Table 7) against the background of the presence of significant intrabreed stratification. Similar results were obtained earlier when analyzing the intrabreed stratification of the Large White pigs (Lugovoy et al., 2017).

One of the consequences of intrabreed stratification is an increasing in the level of interherd diversity (which turns out to be not lower than the level of interbreed diversity) against the background of a decreasing in variability within individual herds. We noted this during ordination of pig herds in the space of first two axes from a Principal Coordinate Analysis (Fig. 1a). In this case, the location of the herd centroids is random and is not consistent with their breed affiliation at all. However, when all individuals belonging to the same breed are combined, the breed centroids in the space of first two axes from a Principal Coordinate Analysis form two clusters that clearly reflect interbreed differences (Fig. 1b).

The decrease in in the level of genetic diversity within individual pig herds is associated in both the relatively frequent manifestation of the bottleneck effect (Table 11) and the high level of inbreeding, which is confirmed by a significant linkage disequilibrium recorded in most of the studied pig herds (especially in LW1, DR1, YR1 and LN1) and a high estimate of average correlation between alleles (Table 14).

In six pig herds the Ne estimates were below 50 inds., in two herds they were in the range of 50-100 inds., and finally in three herds the $\mathrm{Ne}$ estimates exceeded 100 inds. (Table 13). A similar situation was noted for the Large White breed (a widespread breed) and in other countries - $\mathrm{Li}$ thuania: $\mathrm{Ne}=20-38$ inds. (Šveistiene \& Razmaite, 2013), Czech Republic: $\mathrm{Ne}=50$ inds. (Krupa et al., 2015) and Brazil: $\mathrm{Ne}=40$ inds. (Zanella et al., 2016). The estimate of the effective population size in the local breed of Ukraine (Ukrainian Meat breed) was only 68 inds. (with a 95\% confidence interval - 52-92 inds.) (Lugovoy et al., 2018). It is typical that the estimates of the Ne obtained for natural populations of wild boar (Sus scrofa L., 1758), on the contrary, indicate their satisfactory condition (for Spain/Portugal: $\mathrm{Ne}=180$ inds. (Herrero-Medrano et al., 2013); for Australia: $\mathrm{Ne}=960-1477$ inds. (Cowled et al., 2008).

The results of hierarchical analysis of molecular variance (AMOVA) for the studied herds of pigs showed that the average estimate of interherd genetic differentiation (ФРT) is $0.237(\mathrm{P}<0.001)$, and most of this interherd variability was due to intrabreed differences between individual herds within their breed $(\Phi \mathrm{PB}=0.233 ; \mathrm{P}<0.001$, Table 8$)$. A significant interherd component was also noted when studying the genetic variability of donkey breeds on different farms (Colli et al., 2013). Thus, the most striking manifestation of intrabreed stratification is the high estimate of the genetic differentiation measure (Fst) obtained in the analysis of intrabreed groups (herds, farms, etc.), which turns out to be no lower than when comparing different breeds.

For the studied pigs, the Fst estimates in all cases significantly differed from zero $(\mathrm{P}<0.001)$ and varied from 0.067 (for two herds of the YR breed) to 0.168 (for two herds of the DR breed, Table 6). Whereas when comparing individual breeds, the value of the genetic differentiation index was lower ( $F s t=0.065)$, although it also significantly differed from zero $(\mathrm{P}<0.001)$. When analyzing the intrabreed variability of Large White pigs, represented by 4 separate herds, the estimate of the genetic differentiation index (Fst) was $0.148 \pm 0.049$ (Lugovoy et al., 2017), i.e., it was close to the value which was noted in this study.

In general, the obtained estimates of intrabreed differentiation were approximately at the same level as the analogous values obtained in the analysis of interbreed differentiation of pigs: Mexico $-\mathrm{Fst}=0.110$ (Lemus-Flores et al., 2001), the Iberian Peninsula - Fst $=0.130$ (Martınez et al., 2000), Brazil - Fst $=0.140$ (Sollero et al., 2009), Portugal - Fst $=$ 0.184 (Vicente et al., 2008). When analyzing 48 European breeds of pigs, the value of interbreed genetic differentiation was higher $(\mathrm{Fst}=0.210$; SanCristobal et al., 2006), although it was only slightly higher than the one obtained when analyzing two herds of Duroc pigs in our study (Fst $=$ 0.168). Expectedly higher Fst estimates were obtained when both European and Asian (Chinese and Korean) pig breeds, as well as wild boar, were included in the analysis ( $\mathrm{Fst}=0.261$; Kim et al., 2005).

It is typical that the estimates of intrabreed differentiation (Fst) obtained by us for commercial breeds of pigs are close to the estimates obtained in the study of intrabreed stratification (genetic differentiation between different herds) among sheep (Fst $=0.100-0.170$; Dumasy et al., 2012) and goats $(\mathrm{Fst}=0.070)$ (Serrano et al., 2009).

\section{Conclusion}

The analysis of the genetic variability of pigs of four commercial breeds showed that the high level of interbreed differences is caused, first of all, by the high variability among pig herds within each studied breed. Such intrabreed stratification can be formed due to the manifestation of many causes: different genetic basis of the founders of intrabreed genealogical groups, geographical isolation, different directions of selection within individual herds, exchange of animals between separate herds, the use of inbreeding in the practice of selection together with isolation, etc. Important consequences of intrabreed stratification are an increase in the level of interherd diversity (which is not lower than the level of interbreed diversity) against the background of a decrease in variability within individual herds, as well as a significant deficit of heterozygotes and an increasing in the role of negative genetic and demographic processes.

Thus, the existence of genetic heterogeneity within commercial pig breeds should be considered as an essential element in the history of their formation and breeding.

This work was supported by the RFBR grant No. 20-3480004 / 20, as well as with the financial support of the Ministry of Education and Science of Ukraine (state registration number $0119 \mathrm{U} 001042$ ).

\section{References}

Alves, J. M., Carneiro, M., Afonso, S., Lopes, S., Garreau, H., Boucher, S., Allain, D., Queney, G., Esteves, P. J., Bolet, G., \& Ferrand, N. (2015). Levels and patterns of genetic diversity and population structure in domestic rabbits. PloS One, 10(12), e0144687.

Bjömerfeldt, S., Hailer, F., Nord, M., \& Vilà, C. (2008). Assortative mating and fragmentation within dog breeds. BMC Evolutionary Biology, 8(1), 28.

Chang, M. L., Yokoyama, J. S., Branson, N., Dyer, D. J., Hitte, C., Overall, K. L., \& Hamilton, S. P. (2009). Intrabreed stratification related to divergent selection regimes in purebred dogs may affect the interpretation of genetic association studies. Journal of Heredity, 100(suppl. 1), S28-S36.

Chmurzynska, A., Mackowski, M., Szydlowski, M., Melonek, J., Kamyczek, M., Eckert, R., Różycki, M., \& Switonski, M. (2004). Polymorphism of intronic microsatellites in the A-FABP and LEPR genes and its association with productive traits in the pig. Journal of Animal and Feed Sciences, 13(61), 615-624.

Colli, L., Perrotta, G., Negrini, R., Bomba, L., Bigi, D., Zambonelli, P., Verini Supplizi, A., Liotta, L., \& Ajmone-Marsan, P. (2013). Detecting population structure and recent demographic history in endangered livestock breeds: the case of the Italian autochthonous donkeys. Animal Genetics, 44(1), 69-78.

Comuet, J. M., \& Luikart, G. (1996). Description and power analysis of two tests for detecting recent population bottlenecks from allele frequency data. Genetics, 144(4), 2001-2014.

Cowled, B. D., Aldenhoven, J., Odeh, I. O., Garrett, T., Moran, C., \& Lapidge, S. J. (2008). Feral pig population structuring in the rangelands of eastern Australia: Applications for designing adaptive management units. Conservation Genetics, 9(1), 211-224. 
Do, C., Waples, R. S., Peel, D., Macbeth, G. M., Tillett, B. J., \& Ovenden, J. R. (2014). NeEstimator v2: Re-implementation of software for the estimation of contemporary effective population size $(\mathrm{Ne})$ from genetic data. Molecular Ecology Resources, 14(1), 209-214.

Dumasy, J. F., Daniaux, C., Donnay, I., \& Baret, P. V. (2012). Genetic diversity and networks of exchange: A combined approach to assess intra-breed diversity. Genetics Selection Evolution, 44(1), 17.

European Cattle Genetic Diversity Consortium (2006). Marker-assisted conservation of European cattle breeds: An evaluation. Animal Genetics, 37(5), 475-481.

Garza, J. C., \& Williamson, E. G. (2001). Detection of reduction in population size using data from microsatellite loci. Molecular Ecology, 10(2), 305-318.

Glowatzki-Mullis, M. L., Muntwyler, J., Pfister, W., Marti, E., Rieder, S., Poncet, P. A. \& Gaillard, C. (2006). Genetic diversity among horse populations with a special focus on the Franches-Montagnes breed. Animal Genetics, 37(1), 33-39.

Hammer, Ø., Harper, D. A., \& Ryan, P. D. (2001). PAST: Paleontological statistics software package for education and data analysis. Palaeontologia Electronica, $4(1), 9$.

Herrero-Medrano, J. M., Megens, H. J., Groenen, M. A., Ramis, G., Bosse, M., Pérez-Enciso, M., \& Crooijmans, R. P. (2013). Conservation genomic analysis of domestic and wild pig populations from the Iberian Peninsula. BMC Genetics, 14(1), 106

Jochová, M., Novák, K., Kott, T., Volek, Z., Majzlík, I., \& Tůmová, E. (2017). Genetic characterization of Czech local rabbit breeds using microsatellite analysis. Livestock Science, 201, 41-49.

Keenan, K., McGinnity, P., Cross, T. F., Crozier, W. W., \& Prodöhl, P. A. (2013). diveRsity: An R package for the estimation and exploration of population genetics parameters and their associated errors. Methods in Ecology and Evolution, 4(8), 782-788.

Kijas, J. W., Townley, D., Dalrymple, B. P., Heaton, M. P., Maddox, J. F., McGrath, A., Wilson, P., Ingersoll, R. G., McCulloch, R., McWilliam, S., Tang, D., McEwan, J., Cockett, N., Oddy, V. H., Nicholas, F. W., \& Raadsma, H. (2009) A genome wide survey of SNP variation reveals the genetic structure of sheep breeds. PloS One, 4(3), e4668.

Kim, T. H., Kim, K. S., Choi, B. H., Yoon, D. H., Jang, G. W., Lee, K. T., Chung, H. Y., Lee, H. Y., Park, H. S., \& Lee, J. W. (2005). Genetic structure of pig breeds from Korea and China using microsatellite loci analysis. Journal of Animal Science, 83(10), 2255-2263.

Korwin-Kossakowska, A., Sender, G., \& Kuryl, J. (2004). Associations between the microsatellite DNA sequence in the IGF1 gene, polymorphism in the ESR gene and selected reproduction traits in F1 (Zlotnicka Spotted $\times$ Polish Large White) sows. Animal Science Papers and Reports, 22(2), 215-226.

Krupa, E., Žáková, E., \& Krupová, Z. (2015). Evaluation of inbreeding and genetic variability of five pig breeds in Czech Republic. Asian-Australasian Journal of Animal Sciences, 28(1), 25-36.

Lazebnaya, I. V., Perchun, A. V., \& Lazebny, O. E. (2020). Intrabreed and interbreed variation of the BOLA-DRB3. 2 gene in the Kostroma and Yaroslavl indigenous Russian cattle breeds. Immunogenetics, 72(6), 355-366.

Lemus-Flores, C., Ulloa-Arvizu, R., Ramos-Kuri, M., Estrada, F. J., \& Alonso, R. A (2001). Genetic analysis of Mexican hairless pig populations. Journal of Animal Science, 79(12), 3021-3026.

Li, F. E., Mei, S. Q., Deng, C. Y., Jiang, S. W., Zuo, B., Zheng, R., Li, J. L., Xu, D. Q., Lei, M. G., \& Xiong, Y. Z. (2008). Association of a microsatellite flanking FSHB gene with reproductive traits and reproductive tract components in pigs. Czech Journal of Animal Science, 53(4), 139-144.

Lugovoy, S. I., Kharzinova, V. R., Kramarenko, S. S., Lykhach, A. V., Kramarenko, A. S., \& Lykhach, V. Y. (2018). Genetic polymorphism of microsatellite loci and their association with reproductive traits in Ukrainian meat breed pigs. $\mathrm{Cy}$ tology and Genetics, 52(5), 360-367.
Lugovoy, S. I., Kramarenko, S. S., \& Lykhach, V. Y. (2017). Intra-breed variation in the Large White pig breed based on the microsatellite DNA polymorphism. Ştiinţa Agricolă, 1,94-98 (in Russian).

Martınez, A. M., Delgado, J. V., Rodero, A., \& Vega-Pla, J. L. (2000). Genetic structure of the Iberian pig breed using microsatellites. Animal Genetics, 31(5), 295-301.

Martínez, A. M., Gama, L. T., Delgado, J. V., Cañón, J., Amills, M., de Sousa, C. B., Ginja, C., Zaragoza, P., Manunza, A., Landi, V., Sevane, N., \& The BioGoat Consortium (2015). The Southwestern fringe of Europe as an important reservoir of caprine biodiversity. Genetics Selection Evolution, 47(1), 86.

Nei, M. (1972). Genetic distance between populations. The American Naturalist, 106(949), 283-292.

Paetkau, D., Calvert, W., Stirling, I., \& Strobeck, C. (1995). Microsatellite analysis of population structure in Canadian polar bears. Molecular Ecology, 4(3), 347-354.

Peakall, R., \& Smouse, P. E. (2012). GenAIEx 6.5: Genetic analysis in Excel. Population genetic software for teaching and research - an update. Bioinformatics, 28(19), 2537-2539.

SanCristobal, M., Chevalet, C., Haley, C. S., Joosten, R., Rattink, A. P., Harlizius, B., Groenen, A. M., Amigues, Y., Boscher, M.-Y., Russell, G., Law, A., Davoli, R., Russo, V., Désautés, C., Alderson, L., Fimland, E., Bagga, M., Delgado, J. V., Vega-Pla, J. L., Martinez, A. M., Ramos, M., Glodek, P., Meyer, J. N. Gandini, G. C., Matassino, D., Plastow, G. S., Siggens, K. W., Laval, G., Archibald, A. L., Milan, D., Hammond, K., Cardellino, R., \& Law, A. (2006). Genetic diversity within and between European pig breeds using microsatellite markers. Animal Genetics, 37(3), 189-198.

Serrano, M., Calvo, J. H., Martínez, M., Marcos-Carcavilla, A., Cuevas, J., González C., Jurado., J. J., \& de Tejada, P. D. (2009). Microsatellite based genetic diversity and population structure of the endangered Spanish Guadarrama goat breed. BMC Genetics, 10(1), 61.

Sollero, B. P., Paiva, S. R., Faria, D. A., Guimarães, S. E. F., Castro, S. T. R., Egito, A. A., Albuquerque, M. S. M., Piovezan, U., Bertani, G. R., \& Mariante, A. D. S. (2009). Genetic diversity of Brazilian pig breeds evidenced by microsatellite markers. Livestock Science, 123(1), 8-15.

Šveistienè, R., \& Jatkauskienè, V. (2008). Analyses of the genetic diversity within Lithuanian white-backed cattle. Veterinarija ir Zootechnika, 44(66), 67-72.

Šveistienè, R., \& Razmaite, V. (2013). Animal genetic resources in Lithuania. Slovak Journal of Animal Science, 46(4), 131-136.

Vicente, A. A., Carolino, M. I., Sousa, M. C. O., Ginja, C., Silva, F. S., Martinez, A. M., Vega-Pla, J. L., Carolino, N., \& Gama, L. T. (2008). Genetic diversity in native and commercial breeds of pigs in Portugal assessed by microsatellites. Journal of Animal Science, 86(10), 2496-2507.

Wiener, P., Sánchez-Molano, E., Clements, D. N., Woolliams, J. A., Haskell, M. J., \& Blott, S. C. (2017). Genomic data illuminates demography, genetic structure and selection of a popular dog breed. BMC Genomics, 18(1), 1-13.

Wilkinson, S., Haley, C., Alderson, L., \& Wiener, P. (2011). An empirical assessment of individual-based population genetic statistical techniques: Application to British pig breeds. Heredity, 106(2), 261-269.

Wilkinson, S., Wiener, P., Teverson, D., Haley, C. S., \& Hocking, P. M. (2012). Characterization of the genetic diversity, structure and admixture of British chicken breeds. Animal Genetics, 43(5), 552-563.

Yeh, F. C., Boyle, T., Rongcai, Y., Ye, Z., \& Xian, J. M. (1999). Popgene, version 1.31. A Microsoft Windows based freeware for population genetic analysis. University of Alberta, Edmonton.

Zanella, R., Peixoto, J. O., Cardoso, F. F., Cardoso, L. L., Biegelmeyer, P., Cantão, M. E., Otaviano, A., Freitas, M. S., Caetano, A. R., \& Ledur, M. C. (2016). Genetic diversity analysis of two commercial breeds of pigs using genomic and pedigree data. Genetics Selection Evolution, 48(1), 24 